\title{
Alterações epigenéticas no transtorno do espectro autista: revisão integrativa de
}

\section{literatura}

\author{
Epigenetic changes in autismo spectrum disorder: na integrative literature review \\ Cambios epigenéticos en el transtorno del espectro autista: una revisión integradora de la literatura
}

Recebido: 15/08/2021 | Revisado: 20/08/2021 | Aceito: 02/09/2021 | Publicado: 04/09/2021

Thays Lorena Bahia Vieira Correia

ORCID: https://orcid.org/0000-0001-8308-8746 Universidade de Itaúna, Brasil

E-mail: lorenathays27@gmail.com

Tatiana Fernanda Queiroz Cunha ORCID: https://orcid.org/0000-0002-6459-2143 Universidade de Itaúna, Brasil

E-mail: tfernandaqueiros@gmail.com

Eduarda Rafaella Resende Andrade ORCID: https://orcid.org/0000-0001-9460-1760 Universidade de Itaúna, Brasil E-mail: pteduarda@hotmail.com

Regina Consolação dos Santos ORCID: https://orcid.org/0000-0002-7393-3210 Universidade de Itaúna, Brasil

E-mail: reginasantos72@outlook.com

Erika Augusta Faria Maciel

ORCID: https://orcid.org/0000-0003-4648-0217 Universidade de Itaúna, Brasil E-mail: erikamaciel@uit.br

Fernanda Marcelino Rezende e Silva ORCID: https://orcid.org/0000-0003-2236-7009 Universidade do Estado de Minas Gerais, Brasil E-mail: fernanda.silva@uemg.br

Liliane Pena

ORCID: https://orcid.org/0000-0001-5521-1719 Universidade do Estado de Minas Gerais, Brasil E-mail: lilip85@yahoo.com.br

Thayane Vieira Carvalho

ORCID: https://orcid.org/0000-0001-8644-8954 Clínica Auge, Brasil

E-mail: thayanevieira100@yahoo.com.br

Heber Paulino Pena

ORCID: https://orcid.org/0000-0002-9122-6827

Universidade de Itaúna, Brasil

E-mail: heberppena@yahoo.com.br

\section{Resumo}

O transtorno de espectro autista (TEA) é um distúrbio que afeta o neurodesenvolvimento da criança e faz com que sua capacidade de interação social, intelectual e seu comportamento sejam menos desenvolvidos. O objetivo desse estudo foi evidenciar como as desordens epigenéticas podem contribuir para o surgimento de crianças autistas, demonstrando como é essencial que se faça pesquisas científicas e busque compreender as características epigenéticas que levam ao desenvolvimento do TEA. O estudo busca realizar uma revisão integrativa de literatura e tem como descritores: "transtorno do espectro autista e as desordens epigenéticas", "autismo", "desordens epigenéticas", "autism spectrum disorder and epigenetic disorders", "autism", "autism spectrum disorder", "disorders epigenetics", a base de dados consultados foram a Pubmed, Scientific Eletronic Library Online (Scielo) e Google acadêmico. Os estudos apontam que o TEA é caracterizado como um transtorno de herança multifatorial e que fatores ambientais, independentes ou em conjunto com os fatores epigenéticos, aumentam o risco desse agravo. Concluímos que as alterações epigenéticas estão associadas ao autismo, assim como as consequências comportamentais e histológicas deste distúrbio.

Palavras-chave: Transtorno de espectro autista; Alterações genéticas; Desordens epigenéticas; Herança multifatorial.

\section{Abstract}

Autism spectrum disorder (ASD) is a disorder that affects children's neurodevelopment and makes their capacity for social and intellectual interaction and behavior less developed. The aim of this study was to show how epigenetic 
disorders can contribute to the emergence of autistic children, demonstrating how essential it is to carry out scientific research and seek to understand the epigenetic characteristics that lead to the development of ASD. The study seeks to carry out an integrative literature review and has as descriptors: "autistic spectrum disorder and epigenetic disorders", "autism", "epigenetic disorders", "autism spectrum disorder and epigenetic disorders", "autism", "autism spectrum disorder", "epigenetics disorders", the databases consulted were Pubmed, Scientific Electronic Library Online (Scielo) and Academic Google. Studies show that ASD is characterized as a multifactorial inheritance disorder and that environmental factors, whether independent or in conjunction with epigenetic factors, increase the risk of this condition. We conclude that epigenetic alterations are associated with autism, as well as the behavioral and histological consequences of this disorder.

Keywords: Autistic spectrum disorder; Genetic changes; Epigenetic disorders; Multifactorial inheritance.

\section{Resumen}

El trastorno del espectro autista (TEA) es un trastorno que afecta el desarrollo neurológico de los niños y hace que su capacidad de interacción social e intelectual y su comportamiento estén menos desarrollados. El objetivo de este estudio fue mostrar cómo los trastornos epigenéticos pueden contribuir a la aparición de niños autistas, demostrando lo fundamental que es realizar investigaciones científicas y buscar comprender las características epigenéticas que conducen al desarrollo de los TEA. El estudio busca realizar una revisión integradora de la literatura y tiene como descriptores: "trastorno del espectro autista y trastornos epigenéticos", "autismo", "trastornos epigenéticos", "trastorno del espectro autista y trastornos epigenéticos", "autismo", "trastorno del espectro autista", "Trastornos de la epigenética", las bases de datos consultadas fueron Pubmed, Scientific Electronic Library Online (Scielo) y Academic Google. Los estudios muestran que el TEA se caracteriza como un trastorno hereditario multifactorial y que los factores ambientales, ya sean independientes o en conjunto con factores epigenéticos, aumentan el riesgo de padecer esta afección. Concluimos que las alteraciones epigenéticas están asociadas al autismo, así como las consecuencias conductuales e histológicas de este trastorno.

Palabras clave: Trastorno del espectro autista; Cambios genéticos; Trastornos epigenéticos; Herencia multifactorial.

\section{Introdução}

O termo autismo surgiu em 1910, intitulado pelo psiquiatra Eugen Bleuler onde foi utilizado, inicialmente, para descrever pacientes com esquizofrenia. No ano de 1940, Leo Kenner, um psiquiatra, deu início a estudos realizando testes em seu primeiro paciente que manifestou regressões no desenvolvimento, agressividade, ausência de respostas e progressivo isolamento. No decorrer do estudo, em 1942, Kenner ainda não tinha uma conclusão a respeito do diagnóstico, o que resultou na expansão do estudo em mais crianças com o desenvolvimento similar, chegando a resultados que o levaram a identificar e confirmar o diagnóstico, levando o psiquiatra a publicar o primeiro artigo em 1943 sobre "Autistic Disturbances of Affective Contact" (Disturbio Autista do Contato Afetivo) (Evêncio \& Fernandes, 2019).

O autismo ocorre em graus variados de comprometimento das comunicações verbal ou não verbal, apresentando sintomas como: comprometimento qualitativo do convívio social, da comunicação, padrões repetitivos de comportamento, interesses e atividades (Freitas et al., 2017). Um dos pontos mais intrigantes de analisar o autismo é como a sua manifestação variável, apresentando casos severos, moderados ou leves (Czermainski et al., 2014; Oliveira \& Sertié, 2017).

O Transtorno do Espectro Autista (TEA) é um grupo de distúrbios do desenvolvimento neurológico de início precoce, que acomete mais indivíduos do sexo masculino e se caracteriza por um comprometimento das habilidades sociais e de comunicação, além de comportamentos estereotipados. Isso nos leva a analisar que as pessoas que desenvolvem o autismo muitas das vezes não possuem habilidades de interação sociais bem desenvolvidas (American Psychiatric Association, 2013).

Esse transtorno é diagnosticado entre o primeiro e segundo ano de vida da criança, podendo ser identificado nos primeiros meses até o sétimo ano de vida. Algumas pesquisas indicam que a taxa do TEA tem crescido exponencialmente nos últimos anos (American Psychiatric Association, 2013; Freitas et al., 2017).

O TEA não é considerado uma adversidade única, mas sim, um distúrbio de maior complexidade, que apresenta diferentes formas e graus de severidade (Freitas et al., 2017). O TEA pode ser classificado em três medidas de percepção, que sucederam em períodos históricos distintos: o primeiro presumia-se ser um transtorno emocional; o segundo no momento em que se modificam a visão científica e também as medidas de intervenção, ou seja, a ciência e a medicina começam a 
compreender o transtorno como uma modificação neurológica, apreendendo o pensamento de "culpa dos pais", porque presumiam que era em razão de uma relação ineficiente entre mãe e filho que o autismo progredia; e o terceiro que se atribui atualmente, nos quais o autismo é enxergado em um ponto de vista evolutivo, como um transtorno de desenvolvimento (Czermainski et al., 2014).

Ainda que a causa não seja completamente conhecida, afirma-se que a anormalidade multifatorial e epigenéticas tem uma prevalência de 80\% dos casos (Freitas, Brunoni \& Mussolini, 2017). Dessa forma, pode-se dizer que existe uma relação entre o TEA e as causas genéticas ${ }^{7}$. A epigenética é um desenvolvimento onde a molécula vai causar uma mudança no fenótipo, sem alterar a sequência do DNA (Silva \& Mulick, 2009).

Uma pesquisa realizada com pais de crianças autistas demonstrou que esse distúrbio está ligado a anormalidade de alguns cromossomos, sendo que essas modificações podem ser ocasionadas por fatores ambientais ou multifacetados. Com isso, ao analisar o TEA é possível dizer que o mesmo tem a sua fundamentação nas alterações epigenéticas que ocorrem com os pais autistas, sendo que tal fato se da pela alteração de diversos genes e cromossomos (Gadia et al., 2004).

Não existe ainda a ligação do autismo com algum gene modificado, sendo que atualmente se acredita que isso ocorre por causa de várias mutações genéticas nas pessoas (Oliveira \& Sertié, 2017). Por outro lado, as mutações são identificadas em um singular par de bases de um pequeno número de genes que vão codificar as proteínas de adesão sináptica com ênfase em SHANK. Proteínas dessa família têm contribuído arduamente para os testes do TEA em camundongos, pois foram descobertas anomalias moleculares no gene que as codificam (Gadia et al., 2004).

A idade dos pais também é um elemento epigenético que interferem em mutações de células germinativas, ou seja, pais com idades mais avançadas apresentam maior probabilidade de sofrerem mutações em suas células, podendo levar ao autismo (Anzaldúa \& Martínez, 2013).

Discute-se atualmente a ocorrência de alterações epigenéticas após exposições a fatores ambientais, considerados como fatores de risco para o autismo. Questiona-se inclusive o papel de fatores nutricionais, como vitamina D e folato, assim como elementos tóxicos como valproato de sodio, bisfenol A (Silva \& Mulick, 2009).

Portanto, este trabalho tem como objetivo evidenciar como as desordens epigenéticas podem contribuir para o surgimento de crianças autistas, demonstrando como é essencial que se faça pesquisas científicas e busque compreender as características epigenéticas que levam ao desenvolvimento do tea.

\section{Metodologia}

O presente estudo refere-se a uma revisão integrativa da literatura, pela qual mostra-se a capacidade de levantamento de dados e informações, através de referências bibliográficas em artigos científicos, tendo como objetivo o conhecimento sobre o tema em discussão, podendo ter acesso a mais detalhes e resultados mais concretos (Soares, et al., 2014).

A revisão integrativa da literatura possui um caminho muito bem sucedido de análise, pois busca fundamentar o seu conhecimento através de pesquisas bem sucedidas realizadas anteriormente, dando uma base sólida para o pesquisador (a) realizar uma nova análise (Soares, et al., 2014).

Após o levantamento dessas informações, foi realizada uma análise de caráter qualitativo, por meio de uma abordagem exploratória e interpretação dos dados coletados.

O desenvolvimento desse estudo originou-se por meio da seguinte pergunta norteadora: Como as desordens epigenéticas podem contribuir para o surgimento de crianças autistas?

Após a leitura na integra foram selecionados artigos que seguiam como critérios de inclusão: os que descreviam sobre o transtorno espectro autista (TEA), as desordens epigenéticas e a relação entre ambos. Como critério de exclusão: trabalhos 
que não envolvessem conhecimentos sobre crianças, adolescentes ou adultos com TEA, artigos que abordavam somente sobre o Transtorno Espectro do autista e relações genéticas, artigos repetidos e com pesquisas incompletas.

A busca de dados foi realizada no período de março do ano de 2021, através de pesquisas por meios eletrônicos em artigos científicos de produções nacionais e internacionais sobre o TEA e as desordens epigenéticas, através das bases de dados das plataformas como: Pubmed, Scientific Eletronic Library Online (Scielo) e Google acadêmico.

Foram usados como descritores nas buscas: "transtorno do espectro autista e as desordens epigenéticas", "autismo", "desordens epigenéticas", "autism spectrum disorder and epigenetic disorders", "autism", "autism spectrum disorder", "disorders epigenetics".

Os dados utilizados foram encontrados por meio da Estratégia PICO, utilizados para levantar questões de buscas que possibilitam a descrição correta das informações e potencializa a melhora na busca nas bases de dados, com foco no propósito da pesquisa impedindo a execução de buscas irrelevantes (Santos et al., 2007).

A análise utilizada na estratégia PICO é demonstrada no Quadro 1 abaixo:

Quadro 1 - Estratégia PICO.

\begin{tabular}{|c|c|c|}
\hline ACRÔNIMOS & DESCRIÇÃO & ANÁLISE \\
\hline $\mathrm{P}$ & Paciente & $\begin{array}{c}\text { Pacientes com diagnostico de Transtorno } \\
\text { espectro autista }\end{array}$ \\
\hline $\mathrm{I}$ & Intervenção ou indicador & Relações das desordens epignéticas \\
\hline $\mathrm{C}$ & Comparação ou controle & Não se aplica \\
\hline $\mathrm{O}$ & Outcomes- desfecho & O que é, e qual a relação entre? \\
\hline
\end{tabular}

Fonte: Santos, Pimenta, Nobre, (2007).

\section{Resultados e Discussão}

Ao longo do presente estudo foram encontradas diversas fontes que debatem sobre o tema discutido, sendo que cada uma contribuiu para a escrita dessa pesquisa de uma forma diferente. Os artigos selecionados foram demonstrados através do fluxograma da Figura 1.

As buscam foram realizadas nas bases de dados Pubmed, Scientific Eletronic Library Online (Scielo) e Google acadêmico, tendo como resultado 2108 artigos, sendo que foram removidos 2050 artigos, por causa da não discussão assertiva sobre o tema. Sendo que foram removidos mais 20 artigos que estavam duplicados, 470 por estarem incompletos e 1560 porque não atendiam os objetivos da pesquisa, realizando então uma seleção de 58 artigos. A seleção dos artigos foi estruturada mediante ao fluxograma da Figura 1, exposto abaixo: 
Figura 1 - Fluxograma do número de artigos encontrados e selecionados após aplicação dos critérios de inclusão e exclusão.

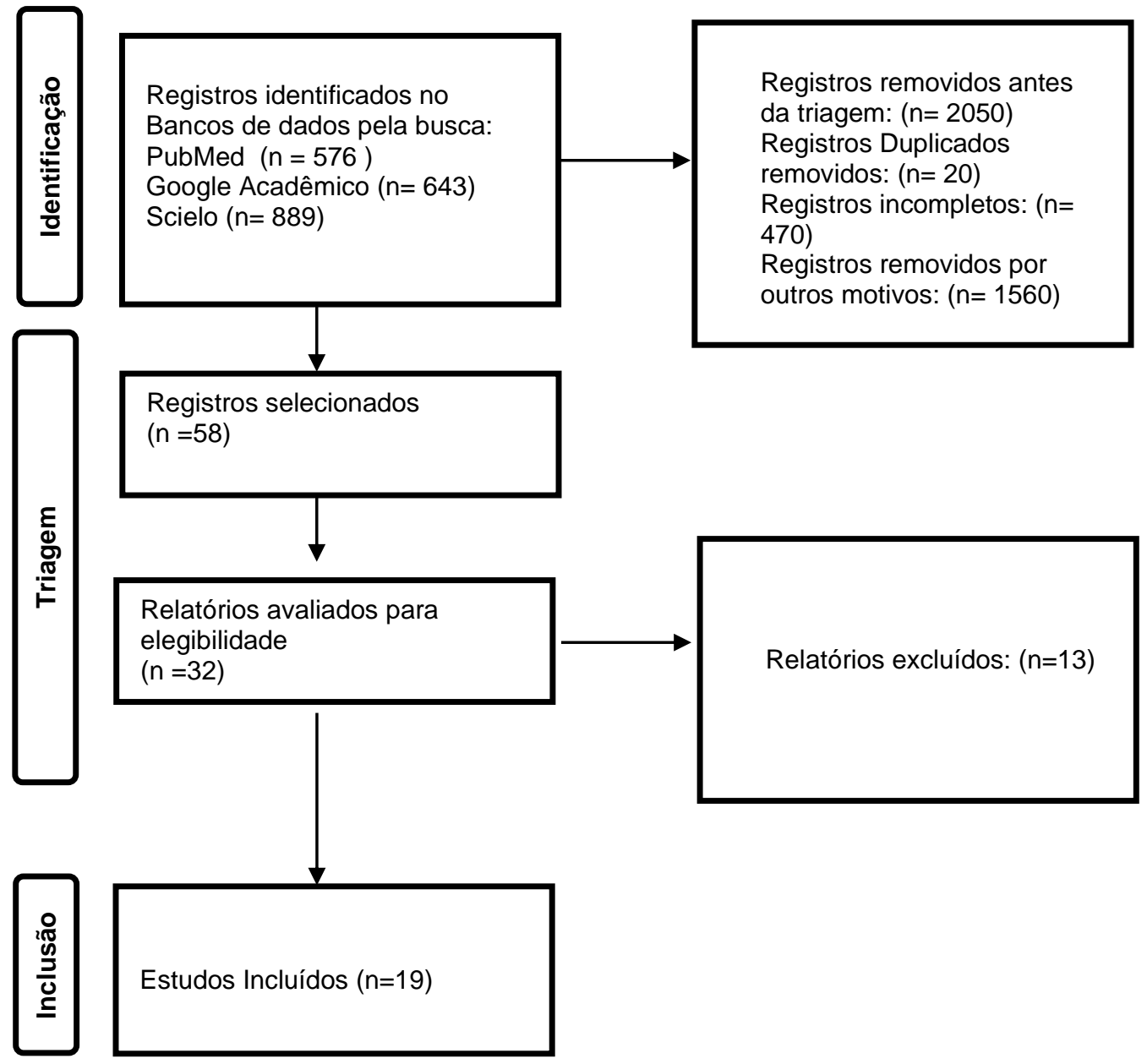

Fonte: Autores.

Após a constatação dos critérios, onde se tinham a seleção de 58 artigos, 32 deles foram avaliados para elegibilidade, e 13 foram excluídos por não adequar-se aos objetivos propostos. Diante disso obteve-se um resultado final de 19 artigos principais, selecionados e originais, que foram agrupados no Quadro 2 a seguir. Onde apresenta a listagem dos artigos para a amostra de acordo com a numeração da ordem de citação, autor, título e o ano de publicação.

Quadro 2 - Referência incluída na Revisão Integrativa de acordo com a numeração, autor, título e ano de publicação.

\begin{tabular}{|c|c|c|c|}
\hline N $^{\circ}$ DA REFERÊNCIA & AUTOR & TÍTULO & ANO \\
\hline 01 & $\begin{array}{c}\text { Evêncio, Kátia Maria de Moura ; } \\
\text { FERNANDES, George Pimentel }\end{array}$ & $\begin{array}{c}\text { História do Autismo : } \\
\text { Compreensões Iniciais }\end{array}$ & 2019 \\
\hline 02 & $\begin{array}{c}\text { FREITAS, Ariane Miranda de; } \\
\text { BRUNONI, Décio e } \\
\text { MUSSOLINI, Juliana Lopes }\end{array}$ & $\begin{array}{c}\text { Transtorno do espectro autista: } \\
\text { estudo de uma série de casos com } \\
\text { alterações genéticas. }\end{array}$ & 2009 \\
\hline 03 & $\begin{array}{c}\text { SILVA, Micheline; MULICK, } \\
\text { James A }\end{array}$ & $\begin{array}{c}\text { Diagnosticando o transtorno } \\
\text { autista aspectos fundamentais e } \\
\text { considerações práticas. }\end{array}$ & 2004 \\
\hline 04 & $\begin{array}{c}\text { GADIA, Carlos A ; TUCHMAN, } \\
\text { Roberto; ROTTA, Newra T }\end{array}$ & $\begin{array}{c}\text { Autismo e doenças invasivas de } \\
\text { desenvolvimento. }\end{array}$ & \\
\hline
\end{tabular}


Research, Society and Development, v. 10, n. 11, e369101119449, 2021

(CC BY 4.0) | ISSN 2525-3409 | DOI: http://dx.doi.org/10.33448/rsd-v10i11.19449

\begin{tabular}{|c|c|c|c|}
\hline 05 & $\begin{array}{l}\text { ANZALDÚA, Adriana Díaz; } \\
\text { MARTÍNEZ, Alejandro Díaz }\end{array}$ & $\begin{array}{l}\text { Contribuição genética, ambiental } \\
\text { e epigenética para a } \\
\text { suscetibilidade aos transtornos do } \\
\text { espectro autista. }\end{array}$ & 2013 \\
\hline 06 & $\begin{array}{l}\text { Hamza M, Halayem S, Mrad R, } \\
\text { Bourgou S, Charfi F, Belhadj A }\end{array}$ & $\begin{array}{c}\text { Implicação da epigenética nos } \\
\text { transtornos do espectro autista: } \\
\text { Uma revisão }\end{array}$ & 2017 \\
\hline 07 & $\begin{array}{c}\text { COUTINHO, João Victor Soares } \\
\text { Coriolano; BOSSO, Rosa Maria } \\
\text { do Vale }\end{array}$ & $\begin{array}{l}\text { Autismo e genetica : uma revisão } \\
\text { de literatura }\end{array}$ & 2015 \\
\hline 08 & $\begin{array}{c}\text { Guedes, Nelzira Prestes da } \\
\text { Silva e Tada, Iracema Neno } \\
\text { CecilioA }\end{array}$ & $\begin{array}{l}\text { Brasileira sobre Autismo na } \\
\text { Psicologia e na Educação. }\end{array}$ & 2015 \\
\hline 09 & $\begin{array}{c}\text { Griesi-Oliveira, Karina e Sertié, } \\
\text { Andréa Laurato }\end{array}$ & $\begin{array}{c}\text { A Produção Científica Brasileira } \\
\text { sobre Autismo na Psicologia e na } \\
\text { Educação }\end{array}$ & 2015 \\
\hline 10 & $\begin{array}{l}\text { A Maia, VB Silva, MR Alves, } \\
\text { MTC Almeida, MF Silveira }\end{array}$ & $\begin{array}{c}\text { Transtorno do Espectro do } \\
\text { Autismo: uma revisão sobre } \\
\text { etiologia, epigenética e mutação } \\
\text { de novo }\end{array}$ & 2017 \\
\hline 11 & $\begin{array}{l}\text { MIELE, Fernanda Gonçalves; } \\
\text { AMATO, Cibelle Albuquerque de } \\
\text { la Higuera. }\end{array}$ & $\begin{array}{l}\text { Transtono do espectro autista: } \\
\text { qualidade de vida e estresse em } \\
\text { cuidadores e/ou familiares - } \\
\text { revisão de literatura }\end{array}$ & 2016 \\
\hline 12 & $\begin{array}{l}\text { Loke, Y.J., Hannan, A. J., \& } \\
\text { Craig, J.M. }\end{array}$ & $\begin{array}{c}\text { O Papel da Mudança Epigenética } \\
\text { nos Transtornos do Espectro } \\
\text { Autista. }\end{array}$ & 2015 \\
\hline 13 & $\begin{array}{c}\text { Eshraghi, AA, Liu, G., Kay, SS, } \\
\text { Eshraghi, RS, Mittal, J., } \\
\text { Moshiree, B., \& Mittal, R. }\end{array}$ & $\begin{array}{l}\text { Epigenética e transtorno do } \\
\text { espectro do autismo: há uma } \\
\text { correlação ?. }\end{array}$ & 2018 \\
\hline 14 & Berko, ER, \& Greally, JM. & $\begin{array}{c}\text { Como a desregulação epigenética } \\
\text { no início da vida embrionária } \\
\text { pode contribuir para o transtorno } \\
\text { do espectro autista. }\end{array}$ & 2015 \\
\hline 15 & Berko, ER et al & $\begin{array}{c}\text { Desregulação epigenética em } \\
\text { mosaico de células ectodérmicas } \\
\text { no transtorno do espectro do } \\
\text { autismo. }\end{array}$ & 2014 \\
\hline 16 & Siu MT, Weksberg R. & $\begin{array}{c}\text { Epigenética do Transtorno do } \\
\text { Espectro Autista. }\end{array}$ & 2017 \\
\hline 17 & Kubota, T., \& Mochizuki, K. & $\begin{array}{c}\text { Efeito Epigenético dos Fatores } \\
\text { Ambientais sobre Transtornos do } \\
\text { Espectro Autista. }\end{array}$ & 2016 \\
\hline 18 & $\begin{array}{c}\text { Laura R. Schaevitz, Joanne E. } \\
\text { Berger-Sweeney. }\end{array}$ & $\begin{array}{l}\text { Interações Gene-Ambiente e } \\
\text { Caminhos Epigenéticos no } \\
\text { Autismo: A Importância do } \\
\text { Metabolismo de Um Carbono }\end{array}$ & 2012 \\
\hline 19 & Adda GM, Cury VE. & $\begin{array}{c}\text { O Enigma Do Autismo: } \\
\text { Contribuições Sobre A Etiologia } \\
\text { Do Transtorno }\end{array}$ & 2016 \\
\hline
\end{tabular}

Fonte: Autores. 
Por fim, os artigos incluídos foram avaliados e estruturados em quatro categorias temáticas identificadas no estudo, como demonstrado na Tabela 1.

Tabela 1 - Distribuição dos artigos de acordo com as categorias temáticas.

\begin{tabular}{lc}
\hline \multicolumn{1}{c}{ Categorias temáticas } & Números de artigos \\
\hline Etiologia do TEA & $12,13,14,15,16,17,18$. \\
Alteração epigenética: Metilação do DNA & $17,18,19,20,21$. \\
Gene e ambiente & $15,22,23,24,25,26$. \\
Implicação da epigenética no TEA & $7,8,11,14,16,17,18,22,24,25,27$. \\
\hline
\end{tabular}

Fonte: Autores.

As categorias foram elaboradas com o intuito de responder o propósito inicial do trabalho, alcançando a ultima etapa da revisão integrativa e enfatizando as prováveis relações epigenéticas com o TEA.

\section{Etiologia TEA}

A etiologia do TEA é definida pela interação entre vários genes (poligênica) e fatores ambientais, caracterizando um transtorno de herança multifatorial ${ }^{11}$. A ampla variabilidade fenotípica do TEA pode refletir a interação entre genes e ambiente, mas também a interação de múltiplos genes dentro do genoma de um indivíduo, e combinações distintas de genes em diferentes indivíduos (Tordjman, et al., 2014).

Alguns estudos com gêmeos monozigóticos (MZ) têm mostrado elevada taxa (acima de 90\%) de herança genética do TEA (Tordjman, et al., 2014). No entanto, em outros estudos, as estimativas de herança genética sugerem uma contribuição similar de fatores genéticos (50\%) e ambientais (50\%) (Bailey, et al., 1995). Em um estudo comparativo com gêmeos MZ e dizigóticos (DZ), concluiu que a taxa de concordância para gêmeos MZ é maior do que a observada paragêmeos DZ; as taxas de concordância variam de acordo com o diagnóstico e com o subtipo de autismo considerado. Além disso, também demonstraram que a taxa de concordância do TEA em gêmeos MZ é incomplet (Bailey, et al., 1995).

Pode-se dizer que a baixa herança genética apontada em alguns estudos e a taxa de concordância incompleta em gêmeos MZ, sugere uma contribuição de fatores ambientais na etimologia do TEA (Coutinho \& Bosso, 2015).

Estudos que buscam compreender o aumento do número dos casos de autismo tem entendido que os fatores ambientais não agem sozinhos, mas estão ligados a um conjunto de fatores genéticos que contribuem para o surgimento desde distúrbio em algumas pessoas (Guedes \& Tada, 2015). No entanto, como ainda não existem estudos que determinam a predominância dos casos de autismo nas pessoas ainda existe uma divergência nos aspectos teóricos, sendo importante levar em consideração as causas em que o autismo está associado, dando uma fundamentação melhor na compreensão de como os fatores ambientais independentes podem estar associados (Guedes \& Tada, 2015).

Alguns estudos moleculares realizados vêm destacando o papel da epigenética no desenvolvimento cerebral como um processo susceptível a influências ambientais, sendo esses potenciais causadores desse distúrbio (Coutinho \& Bosso, 2015; Guedes \& Tada, 2015). 
É uma lacuna a ser preenchida com inúmeras respostas em relação aos fatores que ocasionam o TEA, como a diversidade sintomatológica que o autismo apresenta, refletindo nas tentativas de sistematizar nas manifestações clínicas do transtorno (Griesi-Oliveira \& Sertié, 2017). O que se sabe é que, o TEA é um distúrbio complexo e geneticamente heterogêneo, onde acomete o neurodensevolvimento caracterizado pelo comprometimento das habilidades sociais e de comunicação, além de comportamentos estereotipados (Gadia et al., 2004; Guedes \& Tada, 2015; Silva \& Mulick, 2009).

O TEA acomete cerca de $1 \%$ da população, sendo 4 vezes mais prevalentes nos homens do que em mulheres (Anzaldúa \& Martínez, 2013). Estima-se que algumas causas como, fatores ambientais, infecções ou uso de determinados medicamentos no decorrer da gestação, possuem uma parte na evolução do TEA. Pensa-se também que 50 a $90 \%$ dos casos de Autismo sejam hereditário (Guedes \& Tada, 2015). A relação de vários genes (poligênica) e dos fatores ambientais categoriza uma dificuldade de herança multifatorial (Griesi-Oliveira \& Sertié, 2017). O Transtorno do Espectro Autista recebe este nome de espectro (spectrum), por incluir vários transtornos e pela variação da gravidade e do grau de desenvolvimento (Maia, et al., 2017).

De certo ainda é muito importante realizar estudos moleculares mais completos para que assim se possa entender melhor a etimologia do TEA e assim compreender como as influências ambientais são importantes para o surgimento do mesmo.

\section{Alteração epigenética: metilação do DNA.}

A metilação do DNA funciona controlando o potencial pós-transcricional de uma célula sem alterar a sequência do DNA, assim fazendo a modulação do fenótipo e as expressões dos genes. Ela é uma modificação epigenética que desperta muito interesse de estudos, na qual é influenciada principalmente por fatores ambientais. Também é um tipo de regulação epigenética que se liga com a composição subsequente da cromatina, envolvendo o encadeamento covalente de uma molécula de metila $\left(\mathrm{CH}_{3}\right)$ à citosina do dinucleotídeo $\mathrm{CpG}$ (Miele \& Amato, 2016).

A CpG pode ser modificada na menor parte dos tecidos, e nos momentos do desenvolvimento, podendo se modificar também de outras partes. Por outro lado as citocinas nos $\mathrm{CpGs}$ conseguem ser hidroximetiladas no cérebro, e a metilação do DNA poderá ocorrer em todo o genoma. Regiões regulatórias do genoma apresenta alta densidade de CpG e aumento na metilação, que associa a uma estrutura da cromatina fechada local. Apesar de que pesquisas recentes apontam achados inconclusivos, outras demonstraram o surgimento de biomarcadores de metilação replicados para TEA (Griesi-Oliveira \& Sertié, 2017; Miele \& Amato, 2016).

Em um estudo, foi realizada uma análise da trimetilação da lisina, na proteína histona H3 (H3K4me3), realizado em núcleos neuronais isolados do córtex pré-frontal de cérebros post mortem de 16 indivíduos com autismo, e 16 controles, à sequência do DNA é enriquecido por imunoprecipitação da cromatina (ChIP-seq) onde apresentou-se uma extensão nos picos de H3K4me3 na maioria de pessoas com TEA, isso mostrou a possibilidade de uma regulação anormal da transcrição em cérebros de pessoas com autismo (Loke et al., 2015).

Há uma possibilidade de que algumas mudanças, ou em todas, na metilação do DNA, e modificações pós-tradução das histonas, são secundárias a mutações nos genes que regulam a função da cromatina (Loke et al., 2015). A frequência de mutações neste grupo de genes reguladores da transcrição vem sendo observadas. Um recente estudo usou 3.871 indivíduos com autismo apresentando uma proporção considerável nas mutações em genes que codificaram as proteínas envolvidas na regulação transcricional e da cromatina (Loke et al., 2015).

Ainda que os resultados das mutações desses genes sobre o H3K4me3 ou a metilação do DNA não são bem compreendidos, é possibilidade que as anormalidades epigenômicas afetem as mutações nos genes que regulam a cromatina e a transcrição, em alguns indivíduos. A desregulação epigenética que observamos pode, portanto, representar um resultado 
comum dos efeitos de mutações em tais genes, tornando as alterações epigenéticas um evento secundário a mutações genéticas em indivíduos com TEA (Eshraghi et al., 2018).

Outro fator epigenético identificado também foi à idade materna avançada, em que mães com idade acima de 35 anos no momento do parto, tem uma probabilidade maior de ter um filho autista do que mães com idade inferior. Isso porque pode acontecer uma variação que tem associação da idade do epigenoma e do oócito, proporcionando um risco maior na alteração das características epigenéticas do DNA, podendo então afetar o embrião ${ }^{17}{ }^{18}$. Além disso, alguma alteração no útero também poderá alterar a metilação do DNA, explicado a relação entre a idade materna avançada e a alteração da metilação do DNA (Griesi-Oliveira \& Sertié, 2017; Maia, et al., 2017).

Uma das propriedades decorrente dos genes, em que mutações ou variantes de sequência acontecem em pessoas com TEA, é a da cromatina e propriedades regulatórias epigenéticas, podendo esta mais susceptível em pessoas com TEA que nasceram de mães mais velhas, acometendo um risco maior de acontecimentos mutacionais da idade na linha germinal masculina (Eshraghi et al., 2018).

A metilação do DNA não adequa-se somente no sentido de mensurar a repressão na expressão do gene em dominações impressas, mas fornece também o meio do mecanismo onde os fatores ambientais conseguem ter um resultado de ampla duração no genoma (Eshraghi et al., 2018).

\section{Gene e ambiente}

Alguns fatores ambientais estão presentes no processo da patogênese do autismo, por isso são conhecidos e estudados. Em pesquisas feitas, nota-se que os fatores ambientais e alterações nos genes podem estar relacionados ao TEA, podendo ser denominados como fatores de risco, incluindo os fatores nutricionais: a desnutrição e hormônios e outros fatores como: crianças que sofrem com abuso infantil, pais com problemas psiquiátricos, algumas infecções virais como rubéola e citomegalovírus, produtos químicos incluindo tabaco, solventes, metais, pesticidas entre outros (Berko \& Greally, 2015).

Foram mostrados que as mutações em genes codificam os neurotransmissores, podendo assim ser uma causa de autismo. Um exemplo é a sinapsina, que exerce a função transportadora de proteínas, também presentes no processo de sinapse, se mostrando presentes em pacientes com TEA (Hamza et al., 2016). Essas mutações foram mostradas em fatores de remodelação da cromatina, logo sugerem que há uma relação entre TEA e distúrbios sinápticos (Berko \& Greally, 2015).

Para o diagnóstico clínico ainda não há disponibilidade de testes e diagnósticos específicos, sendo possível então diagnosticar o transtorno através do histórico do paciente e inquérito familiar, a respeito das habilidades comportamentais e cognitivas do paciente em questão. Tendo em vista que ainda existem poucos biomarcadores epigenéticos ambientais replicados, ainda estima-se que as alterações epigenéticas induzidas pelo ambiente, não se apagam durante a gametogênese podendo assim ser transmitidas para gerações seguintes, ocasionando mudanças nos fenótipos de comportamento (Berko \& Greally, 2015; Griesi-Oliveira \& Sertié, 2017).

A epigenética tem natureza reversível, onde pode existir a adição ou remoção de resíduos químicos no DNA, podendo assim ser restaurada. Tendo como um exemplo o uso de medicações para tratar convulsões ou depressões ocasionadas pelo transtorno, que tem a capacidade de restauração genética e epigenética do transtorno em questão (Berko \& Greally, 2015).

Por outro lado, um estudo científico relacionou que além dos medicamentos, a suplementação com acido fólico na gravidez é de grande importância como nutriente ainda na metilação do DNA, reduzindo assim o risco do TEA na prole ${ }^{23}$. Vale ressaltar também a importância de novas descobertas sobre suplementações e medicações, que como apontam as pesquisas, têm resultados positivos sobre a ideia de que fenótipos do TEA causados pelo descontrole epigenéticos, podem sim serem tratados e ate mesmo revertidos (Coutinho \& Bosso, 2015). 
Causas genéticas e ambientais podem modificar padrões da metilação de DNA, em uma dieta materna onde à falta na colina, por exemplo, que poderá acarretar a uma hipometilação global do DNA, aumentando expressividade do gene, que desativam o ciclo celular e possibilita a distinção celular precoce (Berko, et al., 2014). Ainda que anomalias neuroanatômicas sejam eventualmente existentes no Nascimento, os surgimentos dos cardeais sintomas do Autismo transcorrem juntamente com a sinaptogênese e a recomposição da neural nas redes do córtex, em torno de 2 anos de idade (Siu \& Weksberg, 2017).

As modificações dinâmicas nos protótipos de metilação do DNA sucedem no decorrer da vida modulando a expressão gênica. Na evolução embrionária inicial o esboço epigenético é fundamental na regulação dos desenvolvimentos como, inativação do cromossomo $\mathrm{X}$ da impressão dos genes e da diferenciação celular. Já no cérebro, a planificação epigenética aparenta ser mais frágil a intercessões ambientais e genéticas no útero e no inicio da vida após o nascimento (Kubota \& Mochizuki, 2016).

Os fatores ambientais desempenham papel de influenciadores das marcas epigenéticas, no período do pré-natal (Griesi-Oliveira \& Sertié, 2017). Esses fatores são chamados de agentes associativos, que incluem o tabagismo, estresse e doenças gestacionais maternas como: diabetes e hipertensão e idade parental mais avançada (Laura \& Schaevitz, 2012).

A gravidade das características autistas se dá pela duração e intensidade de exposições aos fatores de risco. Porem alguns pesquisadores não concorda que, um único agente ambiental seria responsável pelo autismo, mas sim que deve haver uma predisposição genética na criança (Siu \& Weksberg, 2017). O encadeamento entre gene e o ambiente é uma causa do autismo muito aceita e estudada ultimamente, ou seja, um conjunto de fatores ambientais de risco poderá levar a uma desordem neurológica, levando assim o desenvolvimento do TEA (Laura \& Schaevitz, 2012).

\section{Implicação da epigenética no TEA}

A epigenética tem a função de descrever os fatores moleculares onde se formam complexos em regiões, se dispondo a regulamentar o DNA. Sabe- se que a alteração epigenética inicia-se através de proteínas especificas de sequências ou de RNA's, resultando o recrutamento de escritores epigenéticos ou transferases, que vão adicionar moléculas especificas (Fadda \& Cury, 2016).

O estado epigenético pode ser usado também como um biomarcador de risco do transtorno. Quando se trata de estudos sobre uma doença em especifico, procuram-se pistas sobre as causas, os mecanismos e seus biomarcadores de riscos. Com o Autismo não é diferente, são diversos estudos que foram e estão sendo realizados, onde se buscam a origem, os fatores genéticos e epigenéticos e os fatores ambientais causadores e resultantes do Autismo (Griesi-Oliveira \& Sertié, 2017).

Estudos realizados nos últimos anos direcionam a atenção para à herança transgeracional dos sintomas do TEA, relacionando as marcas epigenéticas, como um fator na etiologia do Autismo. Um exemplo foi uma realização de teste em roedores, onde foram expostos ao acido valproico para a demonstração de que, fenótipos semelhantes ao autista em descendentes masculino, podem ser transmitidos epigeneticamente para terceira geração, no mínimo (Siu \& Weksberg, 2017).

Relaciona-se também que variação da dieta pode contribuir potencialmente como um fator epigenético no TEA (Fadda \& Cury, 2016).

Uma participação minunciosamente considerável de uma circunstância epigenética, com uma alteração inicial, podese ter sentido de que: a condição epigénetica intermedia a causa ou resulta a uma desordenação ${ }^{24}$. Tendo como exemplo de que, se a causa epigenética se tornasse corrente, antecipadamente aos sintomas, ao nascer, e se o fator ambiental estiver correlação a causa epigenética e ao fenótipo da alteração, isso iria nos ajudar nas afirmações de algumas circunstâncias (Berko, et al., 2014). Ressaltando também que a causa epigenética e os fenótipos sofrem influencia por uma combinação de causas ambientais, e genéticas. Causas como interação Gene-ambiente não devem ser ignorados (Griesi-Oliveira \& Sertié, 2017; Maia, et al., 2017). 
A epigenética tem como princípio, explicar efeitos dos fatores ambientais sobre a expressão do gene. Os padrões epigenéticos sofrem interrupções a serem silenciados por inúmeros fatores ambientais, e também por fatores endógenos, sem perder suas propriedades (Coutinho \& Bosso, 2015; Siu \& Weksberg, 2017). Seus mecanismos são hereditários, com um alto grau de complexidade e se mantém estáveis após exposições ambientais, se estabelecendo durante o desenvolvimento do feto e geralmente são mantidos ao longo da vida (American Psychiatric Association, 2013). Porém, algumas modificações epigenéticas se estabelecem em órgãos, podendo ser alteradas após o nascimento, quando o ambiente interno ou externo também sofrerem alterações. Algumas falhas pequenas, ou mesmo a manutenção desses, alteram a fisiologia celular e desencadeiam o desenvolvimento de algumas doenças, como o TEA(Fadda \& Cury, 2016).

Como citado anteriormente, a metilação do DNA é uma das principais modificações epigenéticas, sendo muito estudada no desenvolvimento de doenças neurológicas, e transtornos como o autismo (Coutinho \& Bosso, 2015). Podendo sofrer a influência de fatores ambientais, como relatados, tornando-se uma grande contribuição para desfechos neurológicos, principalmente durante os primeiros estágios do desenvolvimento, quando á o estabelecimento de padrões epigenéticos (Guedes \& Tada, 2015). Com isso, é provável que os eventos ambientais, inconvenientes durante a gestação, induzem a modificações estáveis, e com um prazo maior nos padrões epigenéticos, se tornando presentes até a fase adulta, determinando o risco e principalmente a gravidade do TEA (Maia, et al., 2017).

O TEA é considerado como transtorno de herança multifatorial, onde fatores ambientais, independentes ou juntos com os fatores genéticos, elevam o risco. Estudos moleculares têm salientado as mutações do novo e da epigenética no crescente desenvolvimento do autismo (Anzaldúa \& Martínez, 2013; Gadia et al., 2004).

Tendo em vista que os fatores ambientais podem alterar a expressão dos genes e a função dos mecanismos epigenéticos no desenvolvimento do autismo, o fato de serem controlados com mais facilidade do que os fatores genéticos melhoram as perspectivas para um entendimento mais eficaz, a prevenção e intervenção precoce do TEA (Evêncio \& Fernandes, 2019).

Alterações epigenéticas na metilação de citosina e nas mutações pós-tradução de histonas também contribuem para o mecanismo de modulação da expressão gênica, podendo então sofrer influência pela exibição a fatores ambientais (Freitas, et al., 2017). As Causas do Autismo são evidenciadas, pela função principal dos mecanismos reguladores epigenéticos na patogênese da síndrome do X frágil (FXS) e na síndrome de Rett, que são disfunções de um só gene, geralmente associadas ao TEA (Oliveira \& Sertié, 2017). Sendo uma alteração neurológica complexa que se manifesta de uma mutação no gene, onde codifica a proteína no ligamento do metil-CpG (MeCP2), tendo como principal mediador de regulação epigenética na expressão gênica. A MeCP2 une aos resíduos de citosina metilada, interagindo com complexos na remodelação de cromatina repressivas ao redor do DNA (Kubota \& Mochizuki, 2016).

A FXS (Síndrome do X fragil) acontece diante da ligação da mutação genética e epigenética, onde á o aumento da repetição do trinucleotídeos CGG. A reprodução genômica é um tipo clássico de regulação na expressão gênica, rumo as mudanças epigenéticas ,diante disso uma quantidade elevada de genes não impressos são mensurados pela metilação do DNA ,envolvendo o RELN, sendo apontado como um candidato ao TEA. Tendo em vista que a metilação do DNA pode sofrer modificações pela mutação, exposição maternal, e experiência após o nascimento, ele oferece uma união atingível entre o ambiente e o gene (Maia, et al., 2017).

Ademais, a função de fatores epigenéticos no fundamento crucial da FXS (Síndrome do X fragil) e a síndrome de Rett, sendo distúrbios de gene único relacionando ao TEA, apontam nitidamente que a regulação apropriada da expressão gênica através de meios epigenéticos é critica, para o avanço de circuitos neurais implicados em desempenhos sociais, de linguagem e cognição Humana, em consequência de que a causa do inicio na duplicação do cromossomo 15q, aponta que um único ou mais genes impressos, participem da vulnerabilidade ao Autismo (Laura \& Schaevitz, 2012). 
Pode-se dizer também que, as Alterações nos indícios epigenéticos depois de exposições a fatores ambientais, considerada como um fator de risco ao TEA é analisado em muitos estudos, onde inclui os fatores nutricionais como a vitamina D e folato e os fatores tóxicos como, valproato de sódio e o bisfenol A (American Psychiatric Association, 2013; Evêncio \& Fernandes, 2019).

\section{Considerações Finais}

O TEA é caracterizado como um transtorno de herança multifatorial em que fatores ambientais, independentes ou em conjunto com os fatores epigenéticos, aumentam o risco desse transtorno. Além disso, estudos moleculares têm destacado o papel das mutações de novo e da epigenética no desenvolvimento do TEA. As taxas de mutações de novo em homens, especialmente os homens mais velhos, é geralmente maior do que nas mulheres, principalmente porque nos homens há mais divisões de células germinativas e as modificações epigenéticas ocorrem em maior número nos gametas femininos, em especial das mulheres mais velhas, devido a maior exposição cumulativa nessas células quando comparadas às masculinas.

Diante dos resultados alcançados entende-se através dessa revisão integrativa que, apesar da deficiência de conteúdos mais abrangentes e conclusivos, nota-se que os eventos multifatoriais como, a alteração na metilação de DNA, exposições a fatores de riscos e fatores ambientais, têm uma ligação com o transtorno. A limitação do alcance de resultados claros e precisos dos estudos epigenéticos tem uma dificuldade por existirem vários vieses metodológicos que o tema sofre, impedindo assim sua interpretação.

Os estudos sobre a epigenética e o relacionamento com o Autismo, ainda são muito vagos, tendo muito ainda do que se descobrir. As buscas sobre novos biomarcadores epigenéticos poderão ser usados a favor de futuras intervenções, tendo em vista de que os esforços de pesquisas sobre a epigenética no autismo, poderão nos permitir á um melhor conhecimento sobre a origem do TEA, a relação epigenética, ajudando no desenvolvimento de novos biomarcadores, diagnósticos e tratamento, podendo levar então a uma melhor qualidade de vida aos pacientes com TEA e seus familiares.

Como trabalhos futuros, espera-se o desenvolvimento de mais trabalhos com o foco nos pacientes autistas e sua relação com os profissionais de enfermagem e com os familiares, para que os profissionais sejam mais bem orientados quanto aos atendimentos desses pacientes.

\section{Referências}

American Psychiatric Association (APA). (2013). Diagnostic and statistical manual of mental disorders (5a ed.). American Psychiatric Association.

Anzaldúa, A. D., \& Martínez, A. D. (2013). Contribución genética, ambiental y epigenética en la susceptibilidad a los trastornos del espectro autista. Revista de Neurologia, 57, 556-568.

Bailey, A., Le Couteur, A., Gosttesma, I., Bolton, P., Simonoff, E., Yuzda, E., \& Rutter, M. (1995). Autism as a strongly genetic disorder: evidence from a British twin study. Psychological medicine, 25, 63-67.

Berko, E. R., \& Greally, J. M. (2015). Como a desregulação epigenética no início da vida embrionária pode contribuir para o transtorno do espectro do autismo? Epigenômica, 7 (1), 1-4.

Berko, E. R., Suzuki, M., Beren, F., Lemetre, C., Alaimo, C. M., Calder, R. B., Ballaban-Gil, K. et al. (2014). Desregulação epigenética em mosaico de células ectodérmicas no transtorno do espectro do autismo. PLoS genetics, 10 (5).

Coutinho, J. V. S. C., \& Bosso, R. M. V. (2015). Autismo e genética: uma revisão de literatura. Revista Científica do ITPAC, 8(1).

Czermainski, F. R., Riesgo, R. S., Guimarães, L. S. P., Salles, J. F., \& Bosa, C. A. (2014). Funções Executivas em Crianças e Adolescentes com Transtorno do Espectro do Autismo. Paidéia (Ribeirão Preto), 24(57), 85-94.

Eshraghi, A. A., Liu, G., Kay, S. S., Eshraghi, R. S., Mittal, J., Moshiree, B., \& Mittal, R. (2018). Epigenética e transtorno do espectro do autismo: há uma correlação? Fronteiras em neurociência celular, 12, 78.

Evêncio, K. M. M., \& Fernandes, G. P. (2019). História do Autismo: Compreensões Iniciais. Revista Multidisciplinar de Psicologia, 13(47), 133-138.

Fadda, G. M., \& Cury, V. E. (2016). O enigma do autismo: contribuições sobre a etiologia do transtorno. Psicolestud, 21(3), 411-423. 
Research, Society and Development, v. 10, n. 11, e369101119449, 2021

(CC BY 4.0) | ISSN 2525-3409 | DOI: http://dx.doi.org/10.33448/rsd-v10i11.19449

Freitas, A. M., Brunoni, D., \& Mussolini, J. L. (2017). Transtorno do espectro autista: estudo de uma série de casos com alterações genéticas. Cad. Pós-Grad. Distúrb. Desenvolv, 17(2), 101-110.

Gadia, C. A., Tuchman, R., \& Rotta, N. T. (2004). Autismo e doenças invasivas de desenvolvimento. J. Pediatr, 80(2), 83-94.

Griesi-Oliveira, K., \& Sertié, A. L. (2017). Distúrbios do espectro do autismo: um guia atualizado para o aconselhamento genético. Revista Einstein (São Paulo), 15(2), 233-238.

Guedes, N. P. S., \& Tada, I. N. C. (2015). A Produção Científica Brasileira sobre Autismo na Psicologia e na Educação. Psicologia: Teoria e Pesquisa, 31(3), 303-309.

Hamza, M., Halayem, S., Mrad, R., Bourgou, S., Charfi, F., \& Belhadj, A. (2016). Implication de l'épigénétique dans les troubles du spectre autistique: revue de la littérature [Epigenetics' implication in autism spectrum disorders: A review]. 43(4), 374-381.

Kubota, T., \& Mochizuki, K. (2016). Efeito Epigenético dos Fatores Ambientais sobre Transtornos do Espectro Autista. Revista internacional de pesquisa ambiental e saúde pública, 13(5), 504.

Laura, R. \& Schaevitz, J. E. B. (2012). Interações Gene-Ambiente e Caminhos Epigenéticos no Autismo: A Importância do Metabolismo de Um Carbono. ILAR Journal, 53(3-4), 322-340.

Loke, Y. J., Hannan, A. J., \& Craig, J. M. (2015). O Papel da Mudança Epigenética nos Transtornos do Espectro Autista. Fronteiras na neurologia, 6, 107.

Maia, F. A., Almeida, M. T. C., Silva, V. B., Alves, M. R., \& Silveira, M. F. (2017). Transtorno do Espectro do Autismo: uma revisão sobre etiologia, epigenética e mutação de novo. Revista Norte Mineira de Enfermagem, 6(1), 101-114.

Miele, F. G., \& Amato, C. A. H. (2016). Transtono do espectro autista: qualidade de vida e estresse em cuidadores e/ou familiares - revisão de literatura. Cad. Pós-Grad. Distúrb. Desenvolvimento, 16(2), 89-102.

Oliveira, K. G., \& Sertié, A. L. (2017). Transtornos do espectro autista: um guia atualizado para aconselhamento genético. Revista Einstein, 15(2), $233-238$.

Santos, C. M. C., Pimenta, C. A. M., \& Nobre, M. R. C. (2007). A estratégia do PICO para a pesquisa questiona a construção e a busca de evidências. Revista Latino-Americana de Enfermagem, 15(3): 508-511.

Silva, M., \& Mulick, J. A. (2009). Diagnosticando o transtorno autista: aspectos fundamentais e considerações práticas. Psicol. cienc. prof. , 29(1), 116-131.

Siu, M. T., \& Weksberg, R. (2017). Epigenética do Transtorno do Espectro Autista. Adv Exp Med Biol, 978, 63-90.

Soares, C. B., Hoga, L. A. K., Peduzzi, M., Sangaleti, C., Yonekura, T., \& Silva, D. R. A. D. (2014). Revisão integrativa: conceitos e métodos utilizados na enfermagem. Ver Escola de Enfermagem USP, 48(2).

Tordjman, S., Somogyi, E., Coulon, N., Kermarrec, S., Cohen, D., Bronsard, G., Bonnot, O., et al. (2014). Gene x Environment interactions in autismo spectrum disorders: role of epigenetic mechanisms. Frontiers in psychiatry, 5(53). 